\title{
Rhabdomyoma of the Larynx in a Child with Recurrent Airway Problems
}

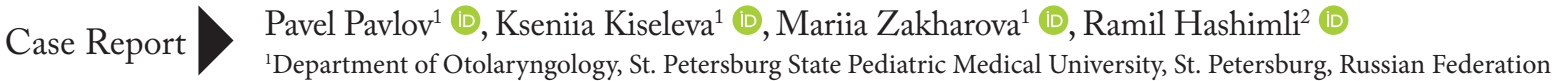 \\ ${ }^{2}$ Department of Otolaryngology, Azerbaijan State Advanced Training Institute for Doctors named after A. Aliyev, Baku, Azerbaijan
}

Abstract

ORCID iDs of the authors: P.P. 0000-0002-4626-201X; K.K. 0000-0001-9746-2516; M.Z. 0000-0001-6410-3533; R.H. 0000-0002-1420-3541.

Cite this article as: Pavlov P, Kiseleva K, Zakharova M, Hashimli R. Rhabdomyoma of the Larynx in a Child with Recurrent Airway Problems. Turk Arch Otorhinolaryngol 2020; 58(2): 137-40.

\section{Corresponding Author:}

Pavel Pavlov, pvpavlov@mail.ru

Received Date: 10.07.2019

Accepted Date: 03.02.2020

Content of this journal is licensed under a Creative Commons Attribution 4.0 International License. Available online at www.turkarchotolaryngol.net
Rhabdomyoma is a rare benign tumor formed from striated muscle tissue and according to the literature occurs quite rarely in the larynx. We present a case of a rhabdomyoma of the larynx in a 5-year-old boy with recurrent airway problems. An extracardiac juvenile rhabdomyoma is extremely rarely found in the field of

\section{Introduction}

Rhabdomyoma is a rare benign tumor formed from striated muscle tissue, its cells in various stages of differentiation. Most cases of this disorder are cardiac, manifesting as a valve abnormality or low cardiac output in young children (1). The extracardiac rhabdomyoma is fairly rare, occurring in less than 2 percent of all striated muscle tumors (2). They are frequently solitary, slow growing lesions. The head and neck are the favorite localizations of extracardiac rhabdomyoma. This is as a result of its cells emerging from the unsegmented mesoderm of the branchial arch during the embryonic development period (3).

Until now, three types of extracardiac rhabdomyomas have been identified, according to histopathological findings:

- the so-called adult type, developing and diagnosed in adulthood;

- the fetal cellular type (also known as juvenile or intermediate rhabdomyoma), which is an extremely uncommon lesion affecting mainly the head and neck, predominantly of male infants. It can be diagnosed during the prenatal period by ultrasound scan (25\% of these lesions reported to date and found postnatally were congenital); otorhinolaryngology. In this report, we presented the diagnostic and therapeutic features of this tumor with the review of the literature.

Keywords: Rhabdomyoma, childhood, larynx, head and neck surgery
An extracardiac juvenile rhabdomyoma is extremely rarely found in the field of otorhinolaryngology, and only a few sporadic cases with laryngeal involvement have been described in the literature, with a predominance of male pediatric patients (5).

\section{Case Presentation}

A 5-year-old boy with Down syndrome, Cushing's syndrome, tracheostomy and oxygen dependence, bronchiolitis obliterans, epilepsy, atopic dermatitis, hypothyroidism, T-cell immunodeficiency was admitted to the ENT department. At the time of admission to the hospital the child had been taking $12.5 \mathrm{mg} /$ day prednisolone for 1.5 years.

He had previously been treated at a local hospital with a diagnosis of recurrent bronchiolitis obliterans by the pediatricians. He had required oxygen support for a long period due to an exacerbation of the bronchial obstruction syndrome so a permanent therapy 
with systemic glucocorticosteroids was started. A thorax computed tomography scanning performed 11 months after showed radiological signs of bronchiolitis obliterans (impairment of pneumatization, atelectasis and lung consolidation on both sides).

Two months later, the child suffered from bilateral polysegmentary pneumonia preceded by shortness of breath with stridor predominant with the inspiratory component and hoarseness of voice. The disease, accompanied by the same symptoms, recurred one month later. The child was entubated and maintained on prolonged ventilation due to the extremely severe breathing disorder. As extubation failed, tracheotomy was performed followed by magnetic resonance imaging (MRI) of the neck which revealed soft tissue hypervascular mass in the lumen of the lar$y n x$, at the level of the vocal folds, measuring $14 \times 8 \times 6 \mathrm{~mm}$. The lumen of the larynx was obstructed. No signs of extralaryngeal growth of the tumor were found (Figure 1).

The child was examined at the ENT Department. Flexible laryngoscopy showed a pale pink formation between the lingual surface of the epiglottis and the anterior laryngeal commissure, which was moving between the vocal folds (Figure 2).

The direct laryngoscopy under general anesthesia demonstrated a large smooth tumor in the left vocal fold. The right side of the larynx was normal. The tumor was removed using contact diode laser and the surrounding tissue was preserved. An area concordant with tracheomalacia was determined in the middle third of the trachea below the tracheotomy.

The histopathological diagnosis was fetal rhabdomyoma based on routine histological and immunohistological staining. The solid tumor was covered with a squamous non-keratinized epithelium; it consisted of bunches of immature muscle fibers. There was no nuclear atypism. The cytoplasmic cross striation was preserved (Figure 3). Mitotic activity was extremely low, which was confirmed by reaction with anti-phosphohistone H3. Immunohistochemical examination showed positive results to antibodies, desmin, Myf4, MyoD1, myoglobin and SMA.

There was no evidence of any recurrence one year after the surgical treatment (Figure 4). The child tolerates the daytime tracheostomy capping without any subsequent respiratory distress or desaturations. The voice has improved. However, decanulation was not performed due to the parent's rejection.

\section{Main Points}

- All patients with dysphonia and symptoms of upper airway obstruction should be examined by otorhinolaryngologist. Flexible laryngeal endoscopy should be performed.

- Early detection and preoperative assessment of rhabdomyoma of the larynx are essential for curative and function-preserving surgical treatment.

- The final diagnosis is based on the histological finding.

- The patient should be observed by a physician for at least a year after surgery.

\section{Discussion}

A rhabdomyoma, like any laryngeal neoplasm, manifests itself with symptoms of impairment of its function, and the order of occurrence of these symptoms depends on the location and size of the tumor. The most common symptoms of laryngeal rhabdomyoma are hoarseness, a foreign-body sensation, dysphagia, airway obstruction (6).

The appearance of new symptoms, such as dysphonia and stridor with inspiratory component in a child with recurrent airway problems should raise the suspicion of another pathology in the upper airway. The deterioration of the child's condition had been regarded as an exacerbation of the underlying disease up to the direct laryngoscopy, performed under general anesthesia. Only then a larynx neoplasm was suspected, and a tracheotomy was applied, which could certainly have been avoided in case of early diagnosis of the pathology.
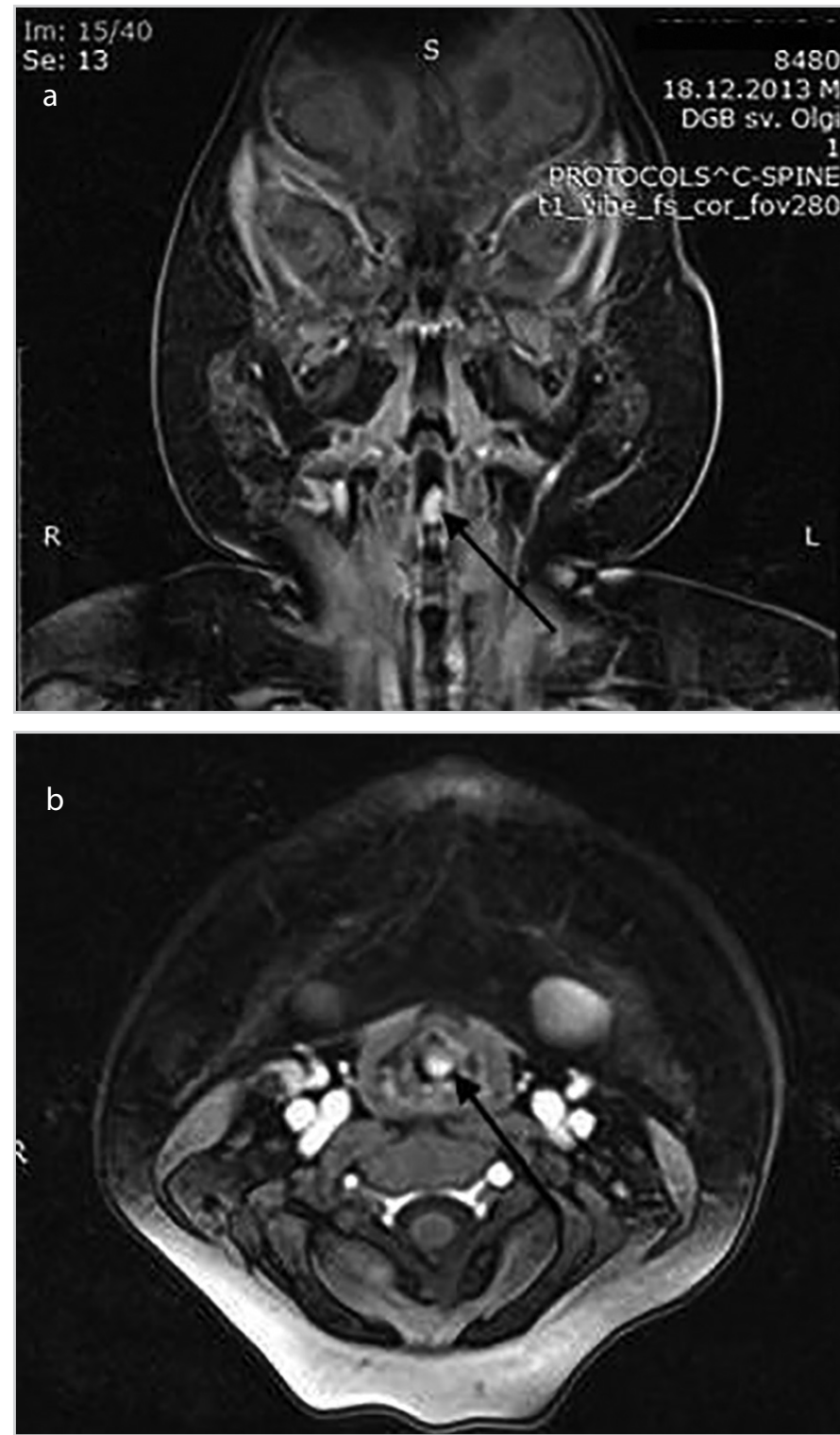

Figure 1 a, b. (a) Magnetic resonance image reveals a soft tissue hypervascular formation in the laryngeal lumen of a 5-year old boy (coronal MRI image). (b) Magnetic resonance image reveals a soft tissue hypervascular formation in the lumen of the larynx in the airway of the 5-year old boy (axial MRI image) 


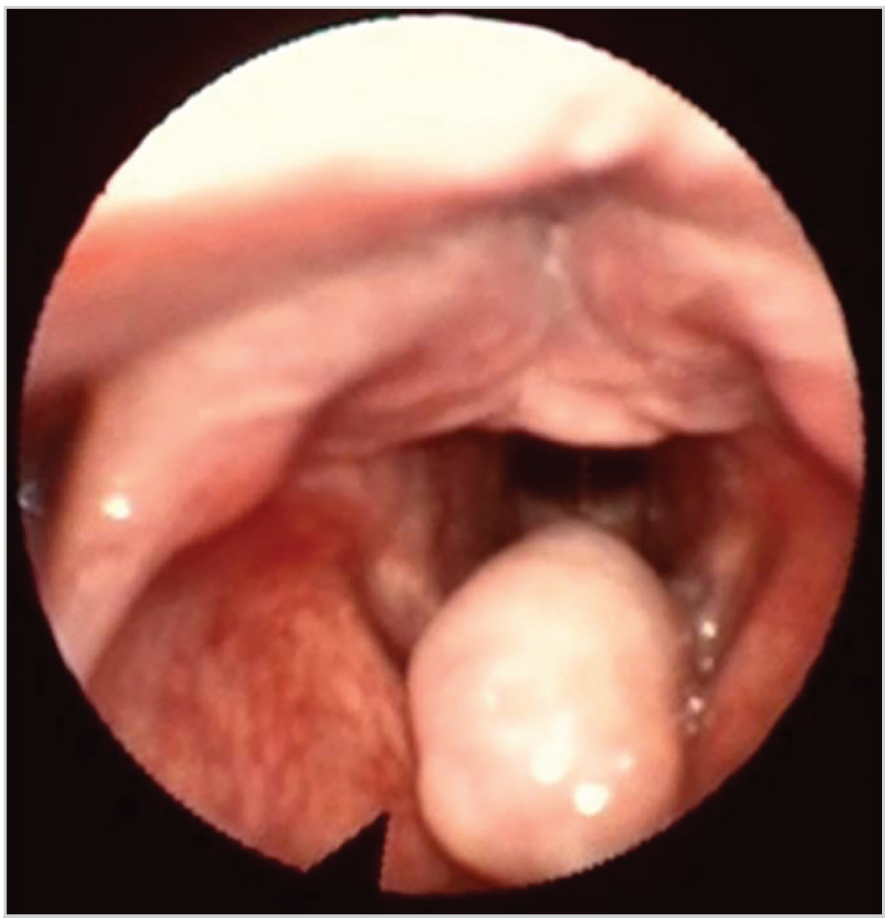

Figure 2. Endoscopic view of the larynx shows the pale pink formation between the lingual surface of the epiglottis and the anterior laryngeal commissure

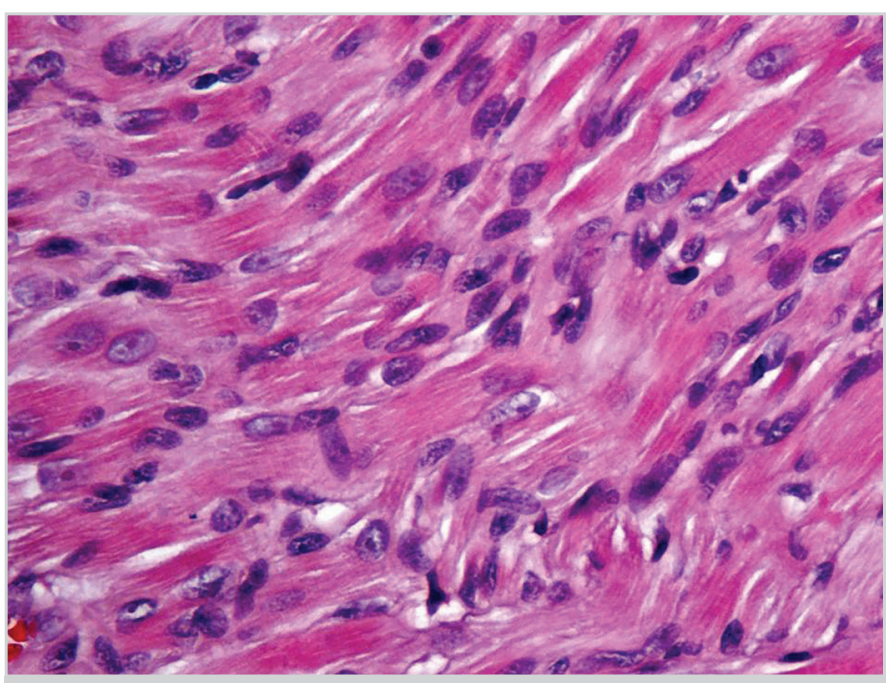

Figure 3. Bunches of immature muscle fibers, staining with hematoxylin and eosin, magnification 400x. Note the cytoplasmic cross striation

So symptoms of dysfunction of the larynx require a complete otolaryngology examination, especially with the use of transnazal flexible endoscope for the detailed visualization of the supraglottic and glottic larynx.

The final diagnosis is based on the histological finding (Figure 3). The myxoid type of the fetal rhabdomyoma may be confused with simple polyps of the vocal fold. A thorough light microscopy is especially essential to differentiate a fetal cell rhabdomyoma from cellular spindle cell sarcomas (7). Differential diagnosis should also include other tumors, these are: teratoma, vascular malformations, neurofibroma, schwannoma, granular cell tumor, paraganglioma, and hamartoma (8-10).

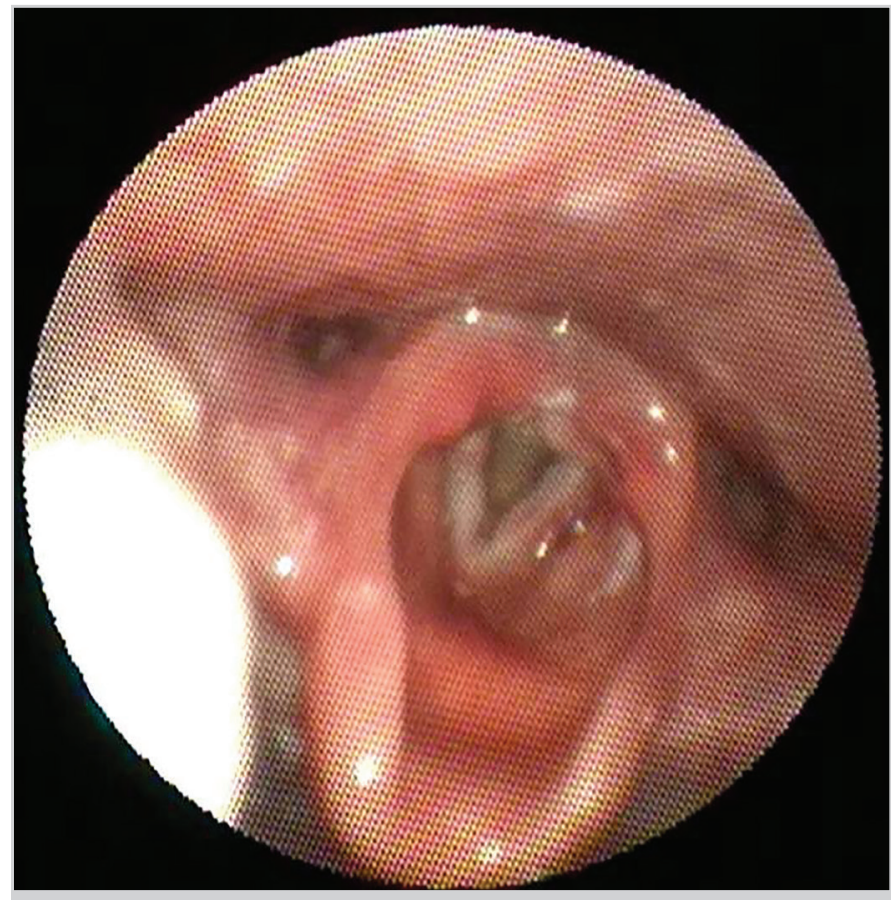

Figure 4. Endoscopic view of the larynx showing no evidence of any recurrence 3 months after the surgical treatment

Thus, it is important to cooperate with an experienced pathologist and to have the diagnosis confirmed with immunohistochemical evaluation.

Surgical treatment, such as an endoscopic removal or an open resection decision can be made according to the size and location of the tumor.

According to the latest data, a higher recurrence rate $(23 \%$ vs. $11 \%$ ) and shorter intervals between the recurrences (4.3 months vs. 6.1 years) were recorded following endoscopic resection, as opposed to the open one. It should be noted that open resection was usually recommended for patients who had slightly larger lesions (11).

In cases where complete removal of the tumor is impossible, re-operations or careful follow-up are necessary to prevent any relapse or an extended revision surgery. If there is a recurrence of the tumor, it is essential to exclude a rhabdomyosarcoma because of close histological similarity. Their differentiation should take into account cytological atypism, increased mitotic activity, necrosis and local invasion (12).

\section{Conclusion}

In a patient who was followed up for a long time due to lower respiratory tract disease, an otolaryngology examination, including transnasal endoscopy, is required in case of symptoms indicating upper respiratory tract pathology such as inspiratory stridor and hoarseness. Laryngeal rhabdomyoma is a quite rare benign tumor especially in the pediatric age.

Informed Consent: Written informed consent was obtained from the parents of the patient. 
Peer-review: Externally peer-reviewed.

Author Contributions: Concept - M.Z.; Design - P.P., M.Z.; Supervision - P.P., R.H.; Materials - K.K.; Data Collection and/or Processing - P.P.; Analysis and/or Interpretation - K.K., R.H.; Literature Search - M.Z.; Writing - K.K.; Critical Reviews - R.H.

Conflict of Interest: The authors have no conflicts of interest to declare.

Financial Disclosure: The authors declared that this study has received no financial support.

\section{References}

1. Enzinger FM, Weiss SW, editors. Soft tissue tumours. 3rd ed. St Louis, Missouri: Mosby-Year-Book, 1995.

2. Willis J, Abdul-Karim FW, di Sant'Agnese PA. Extracardiac rhabdomyomas. Semin Diagn Pathol 1994; 11: 15-25.

3. Carron JD, Darrow DH, Karakla DW. Fetal rhabdomyoma of the posterior cervical triangle. Int J Pediatr Otorhinolaryngol 2001; 61: 77-81. [Crossref]

4. Johansen EC, Illum P. Rhabdomyoma of the larynx: A review of the literature with a summary of previously described cases of rhabdomyoma of the larynx and a report of a new case. J Laryngol Otol 1995; 109: 147-53. [Crossref]
5. Sharma SJ, Kreisel M, Kroll T, Gattenloehner S, Klussmann JP, Wittekindt C. Extracardiac juvenile rhabdomyoma of the larynx: a rare pathological finding. Eur Arch Otorhinolaryngol 2013; 270 : 773-6. [Crossref]

6. Shenoy SV, Rao AR, Prasad V, Kuriakose SM. Rhabdomyoma of larynx - a diagnaostic dilemma. EJENTAS 2013; 14: 21720. [Crossref]

7. Bastian BC, Bröcker EB. Adult rhabdomyoma of the lip. Am J Dermatopathol 1998; 20: 61-4. [Crossref]

8. Kapadia SB, Meis JM, Frisman DM, Ellis GL, Heffner DK, Hyams VJ. Adult rhabdomyoma of the head and neck: A clinicopathologic and immunophenotypic study. Hum Pathol 1993; 24: 608-17. [Crossref]

9. Pai GK, Pai PK, Kamath SM. Adult rhabdomyoma of the esophagus. J Pediatr Surg 1987; 22: 991-2. [Crossref]

10. Helliwell TR, Sisson MCJ, Stoney PJ, Ashworth MT. Immunohistochemistry and electron microscopy of head and neck rhabdomyoma.J Clin Pathol 1988; 41: 1058-63. [Crossref]

11. Ahmed HS, Parikh AS, Srikanth P, Tjoa T, Faquin WC, Lin DT. Asymptomatic rhabdomyoma of the larynx: Case report and review of the literature. Ann Hematol Oncol 2017; 4: 1135. [Crossref]

12. Valdez TA, Desai U, Volk MS. Recurrent fetal rhabdomyoma of the head and neck. Int J Pediatr Otorhinolaryngol 2006; 70: 11158. [Crossref] 